\title{
Assessing the effect of deep inhalation on airway calibre: a novel approach to lung function in bronchial asthma and COPD
}

\author{
R. Pellegrino*, P.J. Sterk+, J.K. Sont+, V. Brusasco
}

Assessing the effect of deep inhalation on airway calibre: a novel approach to lung function in bronchial asthma and COPD. R. Pellegrino, P.J. Sterk, J.K. Sont, V. Brusasco. CERS Journal Ltd 1998.

ABSTRACT: Bronchoconstriction in bronchial asthma and chronic obstructive pulmonary disease (COPD) may be due to decreased airway calibre and/or to the inability of the airways to distend after a deep inhalation (DI). The purpose of this review is to discuss the physiological and clinical relevance of this latter mechanism.

During induced constriction, DI shows remarkable bronchodilatation in normal subjects, but a blunted or null effect in asthmatics. In contrast, during spontaneous bronchospasm DI tends to decrease airway calibre. From a functional point of view, airway inflammation, remodelling, and peripheral bronchoconstriction could prevent airway smooth muscle from stretching.

Therapeutic intervention improving lung function may change the response to DI. For example, bronchodilators allow expiratory airflow before DI to increase more than after DI, because of decreased bronchial hysteresis. This suggest that bronchodilation might be systematically underestimated from parameters derived from maximal expiratory manoeuvres. Inhaled corticosteroids tend to increase the dilator effect of DI, likely due to decreased bronchial and peribronchial oedema.

In conclusion, measuring the effects of deep inhalation on lung function is an easy and simple test able to evaluate the structural changes occurring in the airways and to monitor the effectiveness of therapy.

Eur Respir J 1998; 12: 1219-1227.
*Servizio di Fisiopatologia Respiratoria, Azienda Ospedaliera S. Croce e Carle, Cuneo, Italy. +Dept of Pulmonology, Leiden University Medical Centre, Leiden, The Netherlands. $¥$ Centro di Fisiopatologia Respiratoria, Dipartimento di Scienze Motorie e Riabilitative, Università di Genova, Genoa, Italy.

Correspondence: V. Brusasco

DISM, Università di Genova

Largo R. Benzi, 10

I-16132 Genova

Italy

Fax: 390103537690

Keywords: Bronchial asthma

bronchial challenge

bronchodilatation

chronic obstructive pulmonary disease

maximal and partial flow-volume curves

Received: October 91997

Accepted after revision June 301998
One of the major achievements in pulmonary medicine during the second half of the 20th century is the development and introduction of lung function measurements in the diagnosis and follow-up of patients with asthma or chronic obstructive pulmonary disease (COPD). This has led to international recommendations for standardized lung function testing, which have been widely adopted [1, 2].

The presence and severity of airflow limitation can be documented by measuring the resistance of airways, lungs and/or respiratory system during quiet tidal breathing. Alternatively, forced expiratory flows and volumes, obtained from the maximal expiratory flow-volume (MEFV) curve, are highly suited to detect airflow limitation. At present, the forced expiratory volume in one second $\left(F^{2} V_{1}\right)$ is first choice in the diagnosis and monitoring of asthma and COPD.

However, it has long been recognized that maximal and forced expiratory breathing manoeuvres by themselves can influence the severity of airflow limitation. This is most certainly due to the preceding full inspiration, which apparently can affect airway calibre in various ways under different circumstances. To the authors' knowledge, this was first described by SALTER [3] in 1859. In patients with asthma H.H. Salter observed that "....on the other hand, the spasm may be broken through, and the respiration for the time rendered perfectly free and easy, by taking a long, deep, full inspiration. In severe asthmatic breathing this cannot be done....". Subsequently, this phenomenon was first quantified by NADEL and TerNeY [4] in 1961.

This observation raises the following questions: 1) Can it be demonstrated by using simple objective measurements? 2) Is there a pathophysiological explanation for the bronchodilation following a deep breath? 3) Why is this phenomenon absent in severe asthma and COPD? 4) Is there any relevance in measuring the effect of a deep inhalation (DI) on airway calibre in clinical practice?

The present review is an attempt to address the pathophysiological, methodological and clinical aspects of the DI in health and disease, particularly in view of the rapid progress in this field of applied airway mechanics during recent years. Such progress has been made possible by the combined usage of pathological and morphometric data, including modern imaging techniques, sophisticated mathematical models, and in vitro and in vivo studies in experimental animals and humans. These developments are summarized below.

\section{Underlying mechanisms}

The calibre of the intrathoracic airways is physiologically determined by a balance between forces that tend to constrict the airways (i.e. airway smooth muscle) and those that prevent narrowing (i.e. lung elastic recoil). Under 
normal conditions, lung elastic recoil is determined by lung volume and volume history. Thus, a decrease in airway calibre due to airway smooth muscle contraction is counterbalanced by the elastic recoil generated by the lung volume at which breathing occurs. This effect is the result of the interdependence between airways and lung parenchyma [5], which is produced by the parenchymal attachments to the airway external walls. The net efficacy of lung volume changes in distending the airways is critically dependent on the structural integrity of the site where the forces of interdependence are operative.

The forces of interdependence tend to make the airways follow the movements of the lung. However, both airways and lung parenchyma behave as imperfect elastic tissues in that they dissipate energy during volume changes, i.e. they exhibit hysteresis [6-9]. According to a theoretical analysis provided by FROEB and MEAD [10], the effect of DI on airway calibre depends on the relative hystereses of airways and lung parenchyma. Stated otherwise, airway calibre may change after DI, depending on the magnitude of the airway and parenchymal elastic recoils (the first tending to contract and the latter to dilate the airways). For example, if airway and parenchymal elastic recoils are the same after an inflating force has been applied to the airways, then airway calibre would not be expected to change (fig. 1a). If, however, the recoils are uneven, and one prevails, or the mechanical inflating stimulus is poorly transmitted to the airways, then changes in lung volume

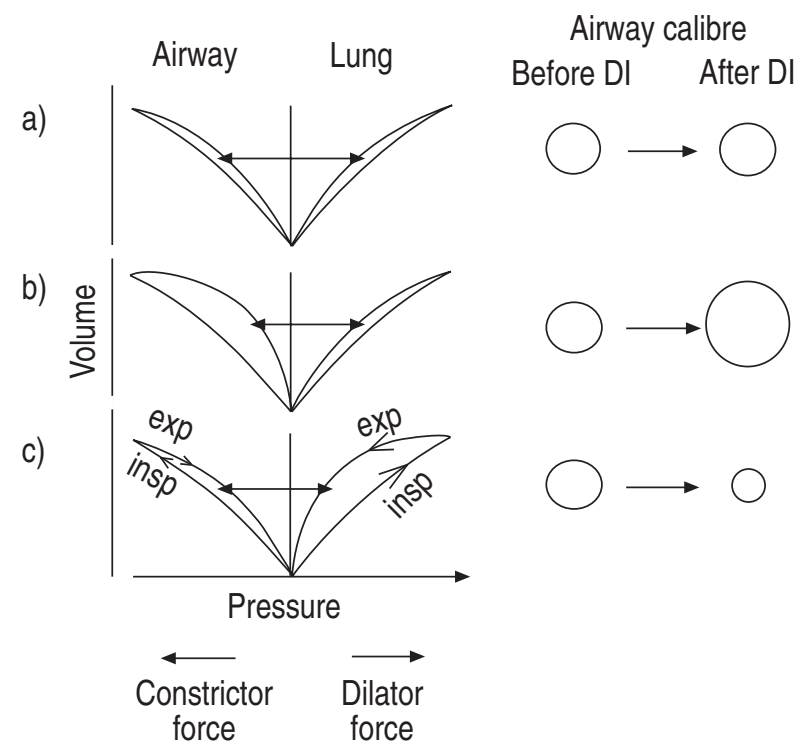

Fig. 1. - Hypothetical examples of the effects of deep inhalation (DI) on airway calibre according to the relative hystereses of lung and airway recoils. Left: Pressure-volume curves of the airways and lung parenchyma during inspiration (insp) and expiration (exp). The area inside the loop is called hysteresis. Note that the elastic recoil of airways is a force that tends to constrict the airways, whereas the elastic recoil of lung is a force that prevents narrowing. Right: Airway calibre before and after DI. a) The elastic recoils of the airways and lung during expiration and hystereses are equal. Therefore, no changes in airway calibre are expected after DI relative to before DI. b) After DI airway elastic recoil decreases relative to lung recoil (relative increase in airway over parenchyma hysteresis). Thus, the prevailing distending force of the lung allows the airway to dilate after DI. c) After DI lung elastic recoil decreases more than airway recoil (relative increase of lung over airway hysteresis). The prevailing airway recoil promotes airway narrowing after a DI. and airway calibre will shift out of phase. Greater decreases in airway than parenchymal elastic recoil after a DI would be expected to cause airway smooth muscle shortening after the stretching action of a DI to lag behind the re-establishment of the lung elastic recoil. This will cause the elastic recoil of the surrounding parenchyma to exceed airway smooth muscle tone, thus leading to a transient bronchodilatation or temporary reopening of closed airways (fig. 1b). The opposite is expected if parenchymal recoil is decreased more than airway recoil after DI (fig. 1c). As airway elastic recoil decreases when smooth muscle is contracted $[7,8]$, the above theory predicts that DI has a bronchodilator effect during bronchoconstriction induced by agents acting directly on airway smooth muscle.

The effectiveness of DI in dilating the airways will depend on the mechanical transmission of the inflating stimulus from the pleura to the external wall of the airways (which in turn depends on the magnitude of elastic recoil, elastic recoil of the lung parenchyma and the forces of interdependence), the thickness of the airways and the dynamic response of its components to stress (smooth muscle and bronchial hysteresis). The adventitia is the anatomical contact area between the airway wall and the lung parenchyma via the alveolar attachments. The elastic recoil pressure provided by lung parenchyma seems to be the strongest modulator of airway narrowing in humans in vivo $[11,12]$. This is caused by its mechanical load, which limits smooth muscle shortening. At small loads (2 $\mathrm{cmH}_{2} \mathrm{O}$ ) the muscle is allowed to contract almost isotonically, whereas at high loads $\left(20 \mathrm{cmH}_{2} \mathrm{O}\right)$ the contraction will approach isometric conditions [13]. MACKLEM [14] recently pointed out that the observed peribronchial swelling in severe asthma may substantially decrease the local parenchymal load, owing to an increase in the external radius of the airways. Theoretically, this can reduce the stretch of airway smooth muscle during a DI, thereby preventing smooth muscle hysteresis from becoming an operative breaking mechanism of airway narrowing [14].

In a subset of asthmatic individuals, DI may unexpectedly induce a transient (10-15 s) bronchodilatation that is followed by a sustained (Ý1 $\mathrm{min}$ ) bronchoconstriction [15-17]. If several consecutive DI are taken, severe constriction progressively develops and may last for $1-2 \mathrm{~h}$. This sustained bronchoconstrictor response cannot be explained by the relative hysteresis theory but seems to be the result of a calcium-dependent airway smooth muscle contraction $[16,17]$. Several mechanisms may account for airway smooth muscle contraction after DI. These include a vagal reflex and a local release of prostaglandins [15], but neither atropine [18] nor cyclooxygenase inhibitors [19] can prevent DI-induced bronchoconstriction. One mechanism able to increase airway smooth muscle active tone without involving neural reflexes or mediators is a myogenic response to stretching [20]. This response can be observed after chemical conversion of multiunit into single unit smooth muscle [20] or after allergic sensitization leading to a greater velocity of shortening by an increase in cross-bridge cycling [21]. It has been suggested that the airways of some asthmatics may exhibit a single-unit behaviour, thus constricting after DI [20].

Starting from the assumption that the direction and magnitude of the effect of DI on airway calibre mainly reflect the balance between the mechanical properties of lung parenchyma and airways [10,22], information on the 
mechanisms and site of constriction may be inferred from the analysis of the changes in flows and resistances induced by DI.

\section{Methodological aspects}

\section{Maximal to partial flow-volume curves}

The expiratory flow obtained with a forced expiration starting from partial inflation $\left(V^{\prime} \mathrm{p}\right)$ is an estimate of airway calibre that is less affected by volume history [23, 24]. By contrast, the expiratory flow obtained with a forced expiration starting from full inflation $(V \mathrm{~m})$ is an estimate of airway calibre as modulated by DI $[23,25]$. The effect of DI on airway calibre can therefore be estimated by comparing $V^{\prime} \mathrm{m}$ and $V_{\mathrm{p}}^{\mathrm{p}}$.

The ratio of $V^{\prime} \mathrm{m}$ to $V_{\mathrm{p}}^{\prime}(\mathrm{M} / \mathrm{P})$ at a given lung volume is the most popular way to estimate the effects of DI on airway calibre [26-38]. The M/P can be easily measured (fig. 2) and interpreted. An M/P >1 means that the expiratory flow increases after DI, thus suggesting a bronchodilator effect, whereas an $\mathrm{M} / \mathrm{P}<1$ suggests a bronchoconstrictor effect. Usually, $\mathrm{M} / \mathrm{P}$ is measured at lung volumes $25-50 \%$ of forced vital capacity (FVC), but it may be sensitive to changes in absolute lung volume. For example, during bronchoconstriction, some individuals have maximal and partial flow-volume curves with different downslopes that terminate approximately at the same residual volume (RV), which would make M/P constant at all lung volumes (fig. 3a). In other individuals, $V_{\mathrm{p}}$ may be reduced more than $V^{\prime} \mathrm{m}$, and the RV attained after the maximal manoeuvre may be less than after the partial manoeuvre (fig. 3b). In this case, the magnitude of $\mathrm{M} / \mathrm{P}$ depends on the lung volume at which it is measured [38]. Hence, when M/P is used to detect the effects of DI on airway calibre, it is strongly recommended that the lung volume is maintained constant relative to total lung capacity (TLC) at which flows are measured.

Assessing the changes of the bronchomotor effect of DI from $\mathrm{M} / \mathrm{P}$ during a bronchial challenge may be compli-

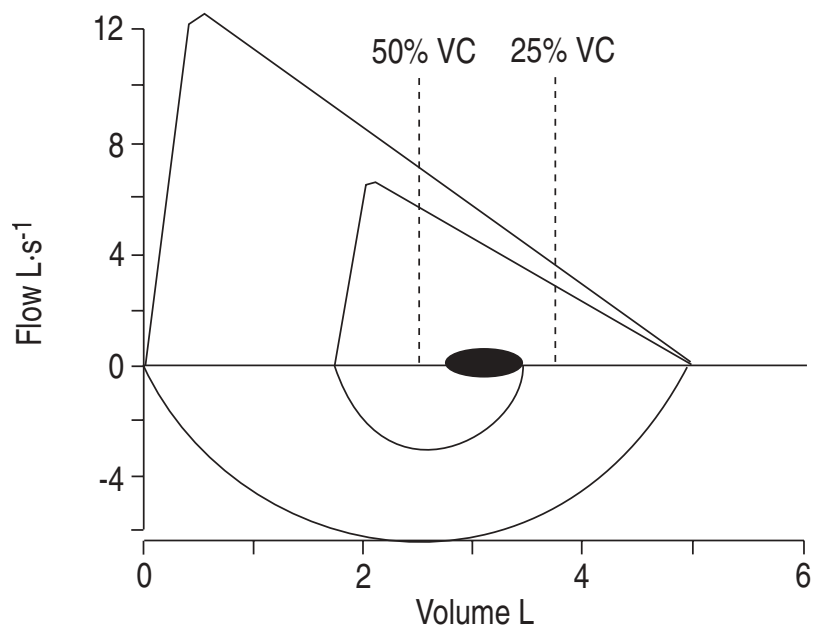

Fig. 2. - Diagrammatic partial and maximal flow-volume curves. Note that the volume at which the partial forced expiration is initiated is about $60 \%$ of vital capacity (VC). The dotted vertical line marks the volume at which the maximal to partial flow ratio $(\mathrm{M} / \mathrm{P})$ is computed $(7.00 / 5.66$ at $50 \% \mathrm{VC} ; 3.40 / 2.75$ at $25 \% \mathrm{VC})$
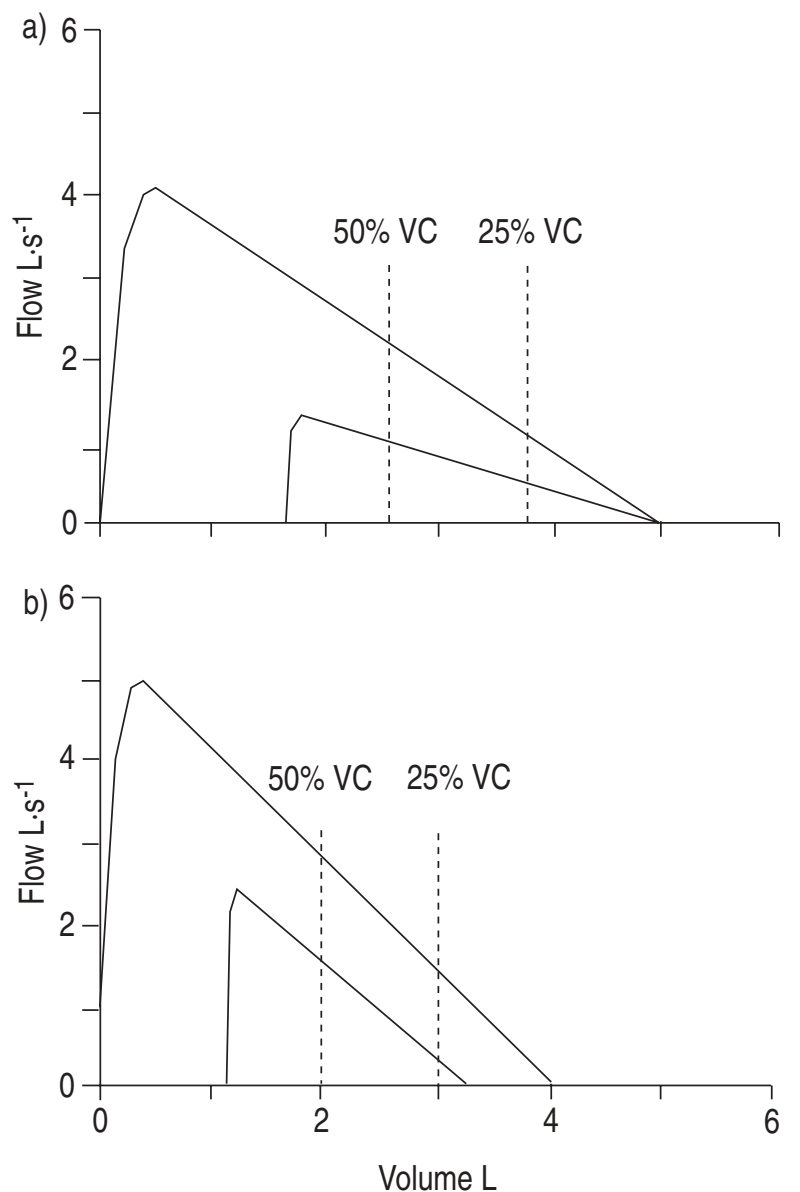

Fig. 3. - Effects of lung volume on maximal to partial flow ratio (M/P). a) $\mathrm{M} / \mathrm{P}$ at $50 \%$ and $25 \%$ of vital capacity $(\mathrm{VC})$ are the same $(\mathrm{M} / \mathrm{P}=2)$ because the downslope of the partial flow-volume curve is decreased compared with the maximal curve, whereas the residual volumes (RV) of the two manoeuvres are the same. b) $\mathrm{M} / \mathrm{P}$ at $25 \% \mathrm{VC}(\mathrm{M} / \mathrm{P}=4.5)$ is higher than at $50 \% \mathrm{VC}(\mathrm{M} / \mathrm{P}=1.8)$ because the partial and maximal flow-volume downslopes are parallel and the RVs are different.

cated by the baseline values. If, for example, $V^{\prime} \mathrm{m}$ decreases from 5.5 to $2.0 \mathrm{~L} \cdot \mathrm{s}^{-1}$ and $V$ p from 4.0 to $0.5 \mathrm{~L} \cdot \mathrm{s}^{-1}$, the $\mathrm{M} / \mathrm{P}$ will increase to a value of 4 . The same absolute $\mathrm{M} / \mathrm{P}$ values will be attained if $V \mathrm{~m}$ decreases from 4.0 to 2.0 $\mathrm{L} \cdot \mathrm{s}^{-1}$ and $V \mathrm{p}$ from 4.5 to $0.5 \mathrm{~L} \cdot \mathrm{s}^{-1}$. Considering only the final $\mathrm{M} / \mathrm{P}$ value would lead to the conclusion that DI reverses the bronchoconstriction equally in both cases. This is obviously not true, as in the first case $V^{\prime} \mathrm{m}$ and $V_{\mathrm{p}}^{\mathrm{p}}$ decreased by the same amount, whereas in the second case $V^{\prime} \mathrm{m}$ decreased less than $V^{\prime}$. However, baseline M/P was different. To overcome this problem, WhEATLEY et al. [39] proposed considering the ratio of the actual effect of DI on flow over the expected maximal possible effect as an index of bronchial reversibility by DI (RI):

$$
\mathrm{RI}=\left(V^{\prime} \mathrm{m}, \mathrm{BC}-V_{\mathrm{p}, \mathrm{Bc}}^{\mathrm{B}}\right) /\left(V^{\mathrm{m}} \mathrm{m}, \mathrm{BL}-V_{\mathrm{p}, \mathrm{BC}}^{\mathrm{p}}\right)
$$

where the subscripts $\mathrm{BC}$ and $\mathrm{BL}$ indicate bronchoconstriction and baseline, respectively. Applying this formula to the above examples shows that DI causes a greater reverse in bronchoconstriction in the second than in the first case (43 versus $30 \%)$.

Another way to quantify the bronchodilator effect of DI during a bronchial challenge is to calculate the slope of 
the linear regression of all $V^{\prime} \mathrm{m}$ values plotted against the corresponding $V_{\mathrm{p}}^{\mathrm{p}}$ values obtained at the same absolute lung volume (MPslope) [40, 41]. With this approach, an MPslope of zero indicates that the bronchodilator effect of DI increases with the severity of bronchoconstriction and completely reverses it (fig. 4a). In contrast, an MPslope of 1 indicates that DI does not affect bronchoconstriction (fig. 4b). This analysis assumes a linear relationship between the changes of $V^{\prime} \mathrm{m}$ and $V_{\mathrm{p}}^{\mathrm{p}}$, which has been confirmed [40, 41]. The MPslope has some advantages over $\mathrm{M} / \mathrm{P}$. Firstly, the MPslope is calculated using the $V^{\mathrm{m}}$ and $V \mathrm{p}$ values measured during the entire challenge. Secondly, the MPslope is linear even when M/P does not change linearly with bronchoconstriction. Thirdly, being calculated over the difference between $V^{\prime} \mathrm{m}$ and $V^{\prime}$, the MPslope is independent of lung volume and thus of thoracic gas compression, which is a volume shift (see below), provided the downslopes of the partial and maximal flow-volume curves remain parallel during induced bronchoconstriction.

Measurements of flow-volume curves at the mouth are affected to a varying extent by thoracic gas compression $[42,43]$. As the exhaled volume lags behind the true lung
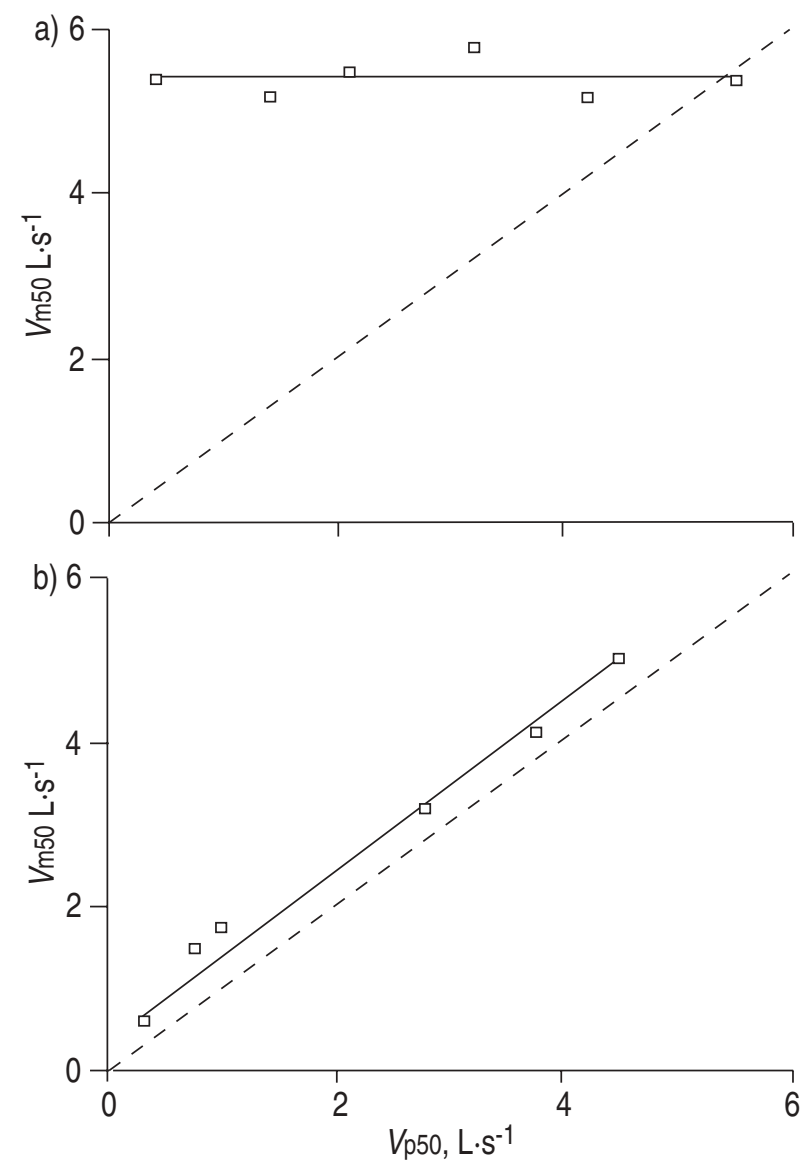

Fig. 4. - Plot of forced expiratory flow at $50 \%$ of control vital capacity recorded after partial and maximal manoeuvres ( $V^{\prime}$ 50 and $\left.V^{\prime} \mathrm{m} 50\right)$. Slope of linear regression of all values recorded during bronchial challenge ( $-\_$) and lines of identify $\left({ }_{-}-{ }_{-}\right)$. a) A hypothetical example in which the decrease in $V^{\top}$ p50 induced by deep inhalation (DI) is associated with unchanged $V^{\prime}$ m50. The slope is zero, which indicates that bronchoconstriction is fully reversed by DI. b) An example in which the decrease in $V_{\mathrm{p} 50}^{\prime}$ is similar to the decrease of $V^{\prime} \mathrm{m} 50$. The slope is 1 , which suggests that DI is totally ineffective in reversing constriction. volume change, the lung volume at which $V^{\prime} \mathrm{m}$ and $V_{\mathrm{p}}^{\mathrm{p}}$ are measured is overestimated. When maximal and partial flow-volume curves do not terminate at the same RV, gas compression will bias $\mathrm{M} / \mathrm{P}$ because of its volume dependence (see fig. 3). Although significant, this effect is small and does not seriously hinder the assessment of DIinduced changes in airway calibre [32, 38]. The MPslope depends on the difference between maximal and partial flows which may increase during induced bronchoconstriction. As long as the downslopes remain parallel during the challenge, the MPslope depends neither on the volume at which it is computed nor on thoracic gas compression [38].

Some technical conditions must be satisfied to make the assessment of the effects of DI from flow-volume curves reliable and reproducible. Recommendations have been issued on how to record maximal flow-volume curves [1,2]. Because of the time dependency of the forced expiratory manoeuvres, the inspiration preceding the forced expiratory manoeuvre should be standardized for both partial and maximal manoeuvres [44]. In addition, the absolute lung volume at which the partial expiratory manoeuvre is intended to start should be known and kept constant when comparisons between maximal and partial flows are made under different conditions, i.e. before and after inhaling bronchodilator or bronchoconstrictor agents. A volume of $50-70 \%$ of control FVC, as matched off from TLC, is generally appropriate (fig. 2) [24, 27]. In practice, a simple way to perform the manoeuvre under control conditions is to ask the patient first to perform a maximal inspiration followed by a maximal expiration, thus allowing inspiratory capacity (IC) and FVC to be measured, and so to calculate the volume between end-tidal expiration, i.e. endexpiratory lung volume (EELV), and the intended percentage of FVC from which the subject will start the partial expiratory manoeuvre. Two minutes later and after regular breathing, the subject will breathe in from EELV to the desired percentage of FVC and then perform the partial expiratory manoeuvre, immediately followed by a maximal expiratory manoeuvre after breathing in to full inflation. After inhaling a bronchoconstrictor or bronchodilator agent, EELV and FVC may vary substantially. Yet, the absolute starting lung volume for the partial expiratory manoeuvre may still be kept constant if the IC is measur-ed approximately $2 \mathrm{~min}$ before the partial manoeuvre in order to calculate the new volume between EELV and the desired percentage of control FVC. This technique as-sumes that TLC does not change systematically during a bronchoconstrictor or bronchodilator challenge, which is a reasonable assumption [45, 46].

Both curves should have sharp peak expiratory flow (PEF), to indicate that the effort was maximal and possibly that gas compression was similar during the two manoeuvres. Finally, $V^{\prime}$ and $V_{\mathrm{p}}$ must be compared at a volume below the notch of the partial curve, far from supramaximal flow.

The assessment of the effect of DI on airway calibre by comparing $V^{\prime} \mathrm{m}$ and $V_{\mathrm{p}}^{\prime}$ may not be appropriate in patients with highly nonhomogeneous lungs, such as cystic fibrosis patients [47]. Fast compartments empty early during forced expiration and contribute little to the late expiration. The relative volume of the fast and slow compartments depends on the volume at which expiration begins $[48]$ and, thus, would influence the M/P ratio. Parallel and 
serial inhomogeneities are also well known to exist in patients with chronic asthma and/or COPD [48]. However, they are probably much less pronounced than in cystic fibrosis and do not account for the differences between partial and maximal flows [47].

\section{Lung and airway resistances}

The effect of DI on airway calibre may also be quantified by comparing lung $(R \mathrm{~L})$ or airway (Raw) resistance before and immediately after DI $[4,19,29,34,41,49$, $50] . R \mathrm{~L}$ is the sum of $R$ aw, which is volume dependent, and tissue viscance, which is both volume and frequency dependent [51]. Any change in breathing pattern or functional residual capacity (FRC) may, therefore, affect the assessment of the effect of DI on airway calibre by using $R \mathrm{~L}$. If the volume-corrected reciprocal of $R$ aw (specific airway conductance, $s G$ aw) is used, the lung volume effect must be taken into account. Even if breathing pattern and FRC do not change, the assessment of the effect of DI by using $R \mathrm{~L}$ or s $G$ aw is complicated because of its remarkable time dependence [52]. Following a DI, $R \mathrm{~L}$ or $\mathrm{s} G$ aw returns

a)
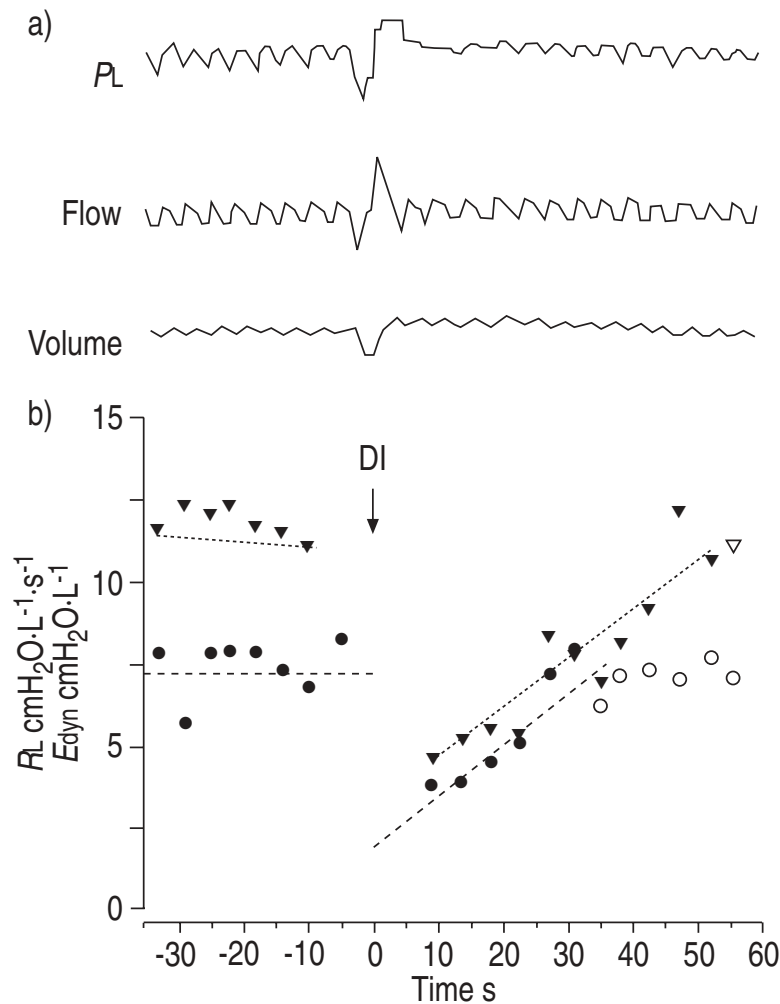

Fig. 5. - a) Strip chart of simultaneous measurements of transpulumonary pressure $(P \mathrm{~L})$, flow and volume. b) Lung resistance $(R \mathrm{~L}$; circles) and dynamic elastance (Edyn; triangles) computed for each breath before and after deep inhalation (DI) in an asthmatic patient during methacholine challenge. Functional residual capacity (FRC) was higher than under control conditions and tidal expiratory flow impinged on maximal flow previously measured during a forced partial expiratory manoeuvre, thus suggesting expiratory flow limitation. Linear regressions of $R \mathrm{~L}$ ( _ _ - ) and $E$ dyn ( _ _ - ) are shown that intercept time zero (subject undertook DI). Open symbols indicate values after a plateau was reached after DI, and were not included in the regression analysis. Note the remarkable time dependence of $R \mathrm{~L}$ and $E$ dyn after DI. Also note that FRC decreased for the first 30-40 s soon after DI (see volume tracing), probably due to the abolition of expiratory flow limitation during tidal breathing. (From [41], with permission). to pre-DI values within 1-2 min [41, 49], but this depends on the airway smooth muscle tone and the magnitude of DI-induced changes [41]. For example, the absolute recovery of $R \mathrm{~L}$ is slow under control conditions but tends to be faster during induced bronchoconstriction [41], and it is similar in asthmatics and normal subjects for a given magnitude of resistance before DI [41, 49]. However, for the same absolute decrease in $R \mathrm{~L}$ after DI, the recovery is faster in asthmatics than in normal subjects [41], probably reflecting a higher velocity of contracted smooth muscle shortening after stretching [21, 53]. It follows that critically quantifying the effect of DI depends on how soon $R \mathrm{~L}$ or $\mathrm{s} G$ aw can be measured after DI (fig. 5). For these reasons, the clinical use of $R \mathrm{~L}$ or $\mathrm{s} G$ aw in the assessment of the effects of DI on airway calibre is generally limited. Only in patients with highly nonhomogeneous lungs is the effect of DI on airway calibre more reliably assessed by changes in $R \mathrm{~L}$ or s $G$ aw than forced expiratory flows.

\section{Clinical patterns}

\section{Normal conditions}

In healthy subjects, as well as in asymptomatic asthmatics with normal lung function, DI causes small or no changes in airway calibre [28, 29, 32, 35-37, 39-41]. This variety of response may result from interindividual differences in baseline bronchial tone, parenchymal hysteresis, mechanical characteristics of airway walls [54], and the forces of interdependence $[14,54,55]$. Even if greater airway smooth muscle tone or airway remodelling may affect the response to DI in asymptomatic asthmatics, it is not possible to distinguish asymptomatic asthmatics from healthy subjects on the basis of the response to DI at baseline [37].

\section{Induced bronchoconstriction}

In healthy subjects, bronchoconstriction induced by inhaled methacholine or histamine is associated with a bronchodilator response to DI that increases proportionally to the increase in airway tone [29, 35-37, 40, 41, 49, 50]. This response is blunted or absent in asthmatics [18, 26, $29,30,33-35,37,40,41,49,50,55]$. This difference might be explained on the basis of the relative hysteresis theory [10] and/or altered airway smooth muscle mechanics [14]. Firstly, airway elastic recoil decreases after taking a DI during airway smooth muscle contraction [7-9], probably owing to changes in the cellular organization of the contractile filaments, which reduce contractility after changes to length during muscle stimulation [56]. If lung elastic recoil does not decrease as much as airway recoil after a DI, then the airways are able to dilate (fig. 1b). This appears to be the case in healthy and mildly asthmatic subjects [29, 35, 36]. In moderate to severe asthmatics, lung recoil may decrease after a DI when constriction has been induced by methacholine [29, 35], probably due to an involvement of the peripheral contractile structures of the bronchial tree (entrance rings of the alveolar ducts) or lung parenchyma (Kapanci cells) [9, 29, 35, 36, 57, 58], or to distortion of lung parenchyma adjacent to constricted 
airways [59]. Under these conditions the tethering forces around the airways become weak and bronchodilatation after a DI no longer occurs or is blunted.

Alternatively, the loss of the bronchodilator effect of DI in relatively severe asthmatics might be explained by inoperative smooth muscle hysteresis, either secondary or not to impaired airway to parenchymal interdependence [14]. Recent model studies indicate that this occurs in the case of peribronchial swelling, probably due to adventitial inflammation itself and/or transport of inflammatory exudate from the (sub)mucosa towards the adventitia [14]. Whether peribronchial oedema might be due to DI itself is not known. This condition mimics a decrease in elastic recoil pressure or a decrease in lung volume $[11,12]$, leading to insufficient airway smooth muscle stretching. FREDBERG et al. [60] recently found evidence suggesting that such mechanical unloading would favour the development of a force-maintenance, latch state of smooth muscle [60]. In addition, mechanical unloading would enable smooth muscle cells to adapt to a shorter length, thus promoting further contraction and bronchoconstriction [61]. Indeed, careful avoidance of inspiratory stretching of the smooth muscle during bronchial challenge with bronchoconstrictors in normal subjects induces airway hyperresponsiveness, similar to [55, 62], or less [63] than that observed in asthma. Finally, it cannot be excluded that the loss of bronchodilator effect of DI can be explained by an increase in the velocity of muscle shortening in asthma $[21,64]$. Then, the restoration of tone following stretch would be unnoticeably quick as opposed to the slow response of smooth muscle to stretch in normal subjects. These observations indicate that the impaired bronchodilation following DI in severe asthma may be due to complex interactions between nonmuscular and muscular mechanisms.

The bronchodilator response to DI is inversely correlated with the airway sensitivity to constrictor agents $[22,35$, $40,50,65,66]$, which suggests that ease of constriction and resistance to stretching share some common mechanisms. For example, airway inflammation could make the airways susceptible to reacting to small doses of constrictor agents and to becoming less compliant. Indeed, the response to DI in asthmatics is associated with cellular markers of inflammation in their bronchoalveolar lavage [31]. In addition, the magnitude of the bronchodilator effect of DI is inversely correlated to the degree of maximal bronchoconstriction $[40,50]$. Thus, healthy or mildly asthmatic subjects with a strong bronchodilator response to DI are likely to have only a limited bronchoconstriction, whereas more severe asthmatics without a bronchodilator response to DI are prone to developing excessive bronchoconstriction. This association between the loss of DI-induced bronchodilation and excessive bronchoconstriction is not unexpected, since both features depend on airway inflammation $[31,67,68]$.

It appears, therefore, that the mechanical relationship between the airways and lung volume modulates the response to bronchoconstrictor stimuli $[14,54]$. This hypothesis is supported by the recent finding $[55,63]$ that prohibiting DI causes healthy individuals to respond to methacholine much like asthmatics. In addition, the inability of the airways to dilate after a DI is correlated to the severity of breathlessness during a bronchial challenge in asthma [69]. This may be one of the reasons for the subjectively perceived inspiratory dyspnoea in the presence of predominantly expiratory flow limitation.

The ability of DI to dilate the airways may depend on the agonist used to induce bronchoconstriction. For a given degree of bronchoconstriction, M/P increases less with histamine, substance $\mathrm{P}$ and hypertonic saline than with methacholine [36, 68, 69]. Furthermore, during the early response to allergen the $\mathrm{M} / \mathrm{P}$ is less than after methacholine [22] but greater than during the late response to allergen [34, 70]. The reduced bronchodilator effect of DI after histamine is probably the result of an increase in lung hysteresis [36, 57]. It can be speculated that the inflammatory events induced by allergens, especially during the late reaction, stimulate the peripheral contractile elements of the lung, thus increasing parenchymal hysteresis and reducing the ability of DI to dilate the contracted airways. Such a blunted dilator effect of DI may also result from peribronchial oedema, which retards the recovery and relaxation of airways after bronchoconstriction [71] and may blunt the transmission of the force of interdependence to the airway walls [14], thus allowing smooth muscle cells to promote further contraction $[60,61]$. The latter mechanism, however, could not be confirmed experimentally [71].

Recognizing the effects of DI on airway calibre is central to the interpretation of bronchial challenges. Airway responsiveness is assessed from the position and shape of the dose-response curve to a constrictor agent. There may be large differences between dose-response curves obtained by measurements with (e.g. FEV1) and without DI (e.g. sGaw or $V^{\prime}$ ). If measurements with DI are used, the dose-response curve may be critically dependent on the number of manoeuvres and the time interval between them [72] and, presumably, on the depth and number of breaths necessary to inhale the agonist. Even a single DI before inhaling methacholine affects the measurements of FEV1 for the next 6 min [72].

\section{Spontaneous bronchoconstriction}

Typically, DI causes a transient decrease in forced expiratory flow in patients with spontaneous asthma attacks or COPD [19, 22, 27, 73]. This effect is greater in patients with more severe obstruction, suggesting that the mechanisms reducing airway calibre are also responsible for the constrictor response to DI. Indeed, spontaneous obstruction in asthma is associated with peribronchial inflammation [74-76], which is likely to impair airway to parenchymal interdependence, thereby precluding bronchodilation and promoting bronchoconstriction after DI [14]. In addition, a peripherally located airway narrowing would result in parenchymal hysteresis prevailing over airway hysteresis, thus resulting in a bronchoconstrictor response to DI [22]. A practical implication of these findings is that the severity of airway obstruction is overestimated if assessed in chronically obstructed patients by measurements with DI.

\section{Effects of deep inhalation on lung volumes}

The changes in airway calibre induced by DI may regulate FRC [41] and RV [37, 77]. Under conditions of 
dynamic hyperinflation, i.e. when the FRC is increased because flow limitation is encountered during tidal breathing, an increase in airway calibre by DI may be associated with a transient decrease in FRC (fig. 5). The increase in airway calibre after DI is also associated with a decrease in RV [37, 77], which is less in asthmatics than in healthy subjects $[37,77,78]$. A delayed occurrence of airway closure or flow limitation after DI may represent the underlying mechanisms [37]. A bronchodilator effect of DI may explain why the RV attained at the end of an expiration starting from TLC is less than that attained at the end of an expiration starting from end-tidal inspiration [79].

\section{Effects of treatments}

Usual doses of inhaled bronchodilators relax airway smooth muscle, thus reducing airway hysteresis, with no effect on lung parenchyma [80]. Consistent with the rela-

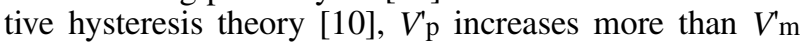
after the inhalation of $\beta$-agonists $[24,80]$. When given by the systemic route or inhaled at higher doses, bronchodilators also decrease parenchymal hysteresis, thus affecting $V_{\mathrm{p}}$ and $V^{r} \mathrm{~m}$ similarly [80]. The clinical consequence of this is that the use of maximal flow-volume curves leads to a systematic underestimation of the bronchodilator response. Such an underestimation could be the reason for the relief of symptoms reported by many patients after inhaling a bronchodilator despite a trivial increase in FEV1 [81].

The only drugs known to restore DI-induced bronchodilatation are glucocorticoids. In asthmatics, long-term treatment with inhaled corticosteroids causes a decrease in airway sensitivity to methacholine and an increase in M/P [33]. The improvement in DI-induced bronchodilatation is not shared by the nonsteroidal anti-inflammatory nedocromil sodium and resembles the effects of both drugs on excessive airway narrowing $[82,83]$. The effect of corticosteroids on $\mathrm{M} / \mathrm{P}$ may reflect a restored effect of interdependence between airway and lung parenchyma, secondary to decreased peribronchial oedema.

\section{Conclusions}

It is remarkable that, until recently, the major physiological breaking mechanism to airway narrowing in humans in vivo has not received much attention in the pathophysiological and clinical research into asthma and COPD. Since it has become apparent that this protective mechanism is impaired or even absent in patients with relatively severe asthma or COPD, it seems essential to unravel the complex airway mechanics involved. The loss of bronchodilation following a DI is associated with clinical symptoms, excessive airway narrowing and inflammation. At present, in asthma, it can only be restored by inhaled corticosteroids.

The recent progress in this field has been due to both the development of accurate lung function techniques to measure the effect of deep breath effects and the increased understanding that the peribronchial area of peripheral airways may be more important in determining the severity and modulation of airway narrowing than the easily accessible (sub)mucosa of the central airways.
Further studies combining newly developed physiological techniques with modern methodology, such as highresolution computed tomography scans [84, 85], video imaging [86] and, if possible, the histology of the airwayparenchymal interface [74, 76], together with in vitro studies [13, 60, 61] and mathematical models [54, 87] are needed to provide more information about the basic mechanisms underlying the effect of deep inhalation in health and disease, which were the subjects of speculation in the present review. Eventually, these studies should lead to specific interventions aimed at preserving and/or restoring airway luminal patency in asthma and chronic obstructive pulmonary disease, by using a manoeuvre widely acknowledged and employed by our patients.

\section{References}

1. Quanjer PhH, Tammeling GJ, Cotes JE, Pedersen OF, Peslin R, Yernault J-C. Standardized lung function testing. Eur Respir J 1993; 6: Suppl. 16, 1-99.

2. American Thoracic Society. Lung function testing: selection of reference values and interpretative strategies. $A m$ Rev Respir Dis 1991; 144: 1202-1218.

3. Salter HH. On Asthma: Its Pathology and Treatment. London, J. Churchill, 1859; pp. 24-60.

4. Nadel JA, Tierney DF. Effect of a previous deep inspiration on airway resistance in man. J Appl Physiol 1961; 16: 717-719.

5. Mead J, Takishima T, Leith D. Stress distribution in lungs: a model of pulmonary elasticity. J Appl Physiol 1970; 28: 596-608.

6. Von Neergaard K. Neue Auffassungen über einen Grundbegriff der Atemmechanik·Die Retraktionskraft der Lunge, abhängig von der Oberflachenspannung in den Alveolen. Z Gesamte Exp Med 1929; 66: 373-394.

7. Sasaki H, Hoppin FG Jr. Hysteresis of contracted airway smooth muscle. J Appl Physiol 1979; 47: 1251-1262.

8. Gunst SJ, Mitzner W. Mechanical properties of contracted canine bronchial segments in vitro. J Appl Physiol 1981; 50: 1236-1247.

9. Ludwig MS, Robatto FM, Simard S, Stamenovic D, Fredberg JJ. Lung tissue resistance during contractile stimulation: structural damping decomposition. J Appl Physiol 1992; 72: 1332-1337.

10. Froeb HF, Mead J. Relative hysteresis of the dead space and lung in vivo. J Appl Physiol 1968; 25: 244-248.

11. Ding DJ, Martin JG, Macklem PT. Effects of lung volume on maximal methacholine induced bronchoconstriction in normal humans. J Appl Physiol 1987; 62: 1324-1330.

12. Cheung D, Schot R, Zwinderman AH, Zagers H, Dijkman JH, Sterk M. Relationship between loss in parenchymal elastic recoil pressure and maximal airway narrowing in subjects with alpha-1-antitrypsin deficiency. Am J Respir Crit Care Med 1997; 155: 135-140.

13. Ishida K, Paré PD, Blogg T, Schellenberg RR. Effects of elastic loading on porcine tracheales muscle mechanics. $J$ Appl Physiol 1990; 69: 1033-1039.

14. Macklem PT. A theoretical analysis of the effect of airway smooth muscle load on airway narrowing. Am J Respir Crit Care Med 1996; 153: 83-89.

15. Gayard P, Orehek J, Grimaud C, Charpin J. Bronchoconstrictor effects of a deep inspiration in patients with asthma. Am Rev Respir Dis 1975; 111: 433-439.

16. Marthan R, Woolcock AJ. Is a myogenic response involved in deep inspiration-induced bronchoconstriction in asthmatics? Am Rev Respir Dis 1989; 140: 1354-1358. 
17. Pellegrino R, Violante B, Crimi E, Brusasco V. Time course and calcium dependence of sustained bronchoconstriction induced by deep inhalation in asthma. Am Rev Respir Dis 1991; 144: 1262-1266.

18. Fish JE, Ankin ML, Kelly JF, Peterman VI. Regulation of bronchomotor tone by lung inflation in asthmatic and nonasthmatic subjects. J Appl Physiol 1980; 50: 1079-1086.

19. Fairshter RD. Airway hysteresis in normal subjects and individuals with chronic airflow obstruction. J Appl Physiol 1985; 58: 1505-1510.

20. Stephens NI. Postjunctional factors in airway smooth muscle hyperresponsiveness. In: Handbook of Physiology, Section 3, Vol. Ill, Part 2. The Respiratory System. Mechanics of Breathing. Bethesda, MD, American Physiological Society, 1986; pp. 719-726.

21. Jiang H, Rao K, Halayko AJ, Kepron W, Stephens NL. Bronchial smooth muscle mechanics of a canine model of allergic airway hyperresponsiveness. J Appl Physiol 1992; 72: 39-45.

22. Ingram RH Jr. Physiological assessment of inflammation in the peripheral lung of asthmatic patients. Review. Lung 1990; 168: 237-247.

23. Hyatt RE. Forced expiration. In: Handbook of Physiology, Section 3, Vol. II, Part 1. The Respiratory System. Mechanics of Breathing. Bethesda, MD, American Physiological Society, 1986; pp. 295-314.

24. Barnes PJ, Gribbin HR, Osmanliev D, Pride NB. Partial flow-volume curves to measure bronchodilator dose-response curves in normal humans. J Appl Physiol 1981; 150: 1193-1197.

25. Olive JT, Hyatt RE. Maximal expiratory flow and total respiratory resistance during induced bronchoconstriction in asthmatic subjects. Am Rev Respir Dis 1972; 106: 366376.

26. Orehek J, Nicoli MM, Delpierre S, Beaupre A. Influence of the previous deep inspiration on the spirometric measurement of provoked bronchoconstriction in asthma. Am Rev Respir Dis 1981; 123: 269-272.

27. Zamel N, Hughes D, Levison H, Fairshter RD, Gelb AF. Partial and complete maximum expiratory flow-volume curves in asthmatic patients with spontaneous bronchospasm. Chest 1983; 83: 35-39.

28. Berry RB, Fairshter RD. Partial and maximal expiratory flow-volume curves in normal and asthmatic subjects before and after inhalation of metaproterenol. Chest 1985; 88: 697-702.

29. Burns CB, Taylor WR, Ingram RH Jr. Effects of deep inhalation in asthma: relative airway and parenchymal hysteresis. J Appl Physiol 1985; 59: 1590-1596.

30. Lim TK, Pride NB, Ingram RH. Effects of volume history during spontaneous and acutely induced airflow obstruction in asthma. Am Rev Respir Dis 1987; 135: 591-596.

31. Pliss LB, Ingenito EP, Ingram RH Jr. Responsiveness, inflammation, and effects of deep breaths on obstruction in mild asthma. J Appl Physiol 1989; 66: 2298-2304.

32. Fairshter RD, Berry RB, Wilson AF, Brideshead T, Mukai D. Effects of thoracic gas compression on maximalandpartialflow-volumemaneuvers.JApplPhysiol 1989; 67: 780-785.

33. Bel EH, Timmers MC, Hermans J, Dijkman JH, Sterk PJ. The long-term effects of nedocromil sodium and beclomethasone dipropionate on bronchial responsiveness to methacholine in nonatopic asthmatic subjects. Am Rev Respir Dis 1990; 141: 21-28.

34. Pellegrino R, Violante B, Crimi E, Brusasco V. Effects of deep inhalation during early and late asthmatic reactions to allergen. Am Rev Respir Dis 1990; 142: 822-825.
35. Brusasco V, Pellegrino R, Violante B, Crimi E. Relationship between quasi-static pulmonary hysteresis and maximal airway narrowing in humans. J Appl Physiol 1992; 72: 2075-2080.

36. Pellegrino R, Violante B, Crimi E, Brusasco V. Effects of aerosol methacholine and histamine on airways and lung parenchyma in healthy humans. J Appl Physiol 1993; 74: 2681-2686.

37. Pellegrino R, Violante B, Selleri R, Brusasco V. Changes in residual volume during induced bronchoconstriction in healthy and asthmatic subjects. Am J Respir Crit Care Med 1994; 150: 363-368.

38. Pellegrino R, Confessore P, Bianco A, Brusasco V. Effects of lung volume and thoracic gas compression on maximal and partial flow-volume curves. Eur Respir J 1996; 9: 2168-2173.

39. Wheatley JR, Paré PD, Engel LA. Reversibility of induced bronchoconstriction by deep inspiration in asthmatics and normal subjects. Eur Respir J 1989; 2: 331-339.

40. Pellegrino R, Violante B, Brusasco V. Maximal bronchoconstriction in humans: relationship to deep inhalation and airway sensitivity. Am J Respir Crit Care Med 1996; 153: 115-121.

41. Pellegrino R, Wilson O, Jenouri G, Rodarte JR. Lung mechanics during bronchoconstriction. J Appl Physiol 1996; 81: 964-975.

42. Ingram RH Jr, Schilder DP. Effects of thoracic gas compression on the flow-volume curve of the forced vital capacity. Am Rev Respir Dis 1986; 94: 56-63.

43. Rodarte JR, Rehder K. Dynamics of respiration. In: Handbook of Physiology, Section 3. Vol. III, Part 1, The Respiratory System. Mechanics of Breathing. Bethesda, MD, American Physiological Society, 1986; pp. 131-144.

44. D'Angelo E, Prandi E, Milic-Emili J. Dependence of maximal flow-volume curves on time-course of preceding inspiration. J Appl Physiol 1993; 75: 1155-1159.

45. Kirby JB, Juniper EF, Hargreave FE, Zamel N. Total lung capacity does not change during methacholine-stimulated airway narrowing. J Appl Physiol 1986; 61: 21442147.

46. Holmes PW, Campbell AH, Barter CE. Acute changes of lung volumes and lung mechanics in asthma and in normal subjects. Thorax 1978; 33: 394-400.

47. Zinman R, Wolil MEB, Ingram RH Jr. Nonhomogeneous lung emptying in cystic fibrosis patients. Volume history and bronchodilator effects. Am Rev Respir Dis 1991; 143: 1257-1261.

48. Melissinos CG, Webster P, Tien YK, Mead J. Time dependence of maximum flow as an index of nonuniform emptying. J Appl Physiol 1979; 47: 1043-1050.

49. Parham JW, Shepard RH, Norman PS, Fish JE. Analysis of time course and magnitude of lung inflation effects on airway tone: relation to airway reactivity. Am Rev Respir Dis 1983; 128: 240-245.

50. Kariya ST, Thompson LM, Ingenito EP, Ingram RH Jr. Effects of lung volume, volume history, and methacholine on lung tissue viscance. J Appl Physiol 1989; 66: 977982.

51. Brusasco V, Warner DO, Beck KC, Rodarte JR, Rehder K. Partitioning of pulmonary resistance in dogs: effect of tidal volume and frequency. J Appl Physiol 1989; 66: 1190-1196.

52. Ingram RH Jr, Pedley TJ. Pressure-flow relationships in the lungs. In: Handbook of Physiology. Section 3, Vol. III, Part 1. The Respiratory System. Mechanics of Breathing. Bethesda, MD, American Physiological Society, 1986; pp. 277-293. 
53. Kong SK, Shiu RPC, Stephens NL. Studies on myofibrillar ATPase in ragweed sensitized canine pulmonary smooth muscle. J Appl Physiol 1986; 60: 92-94.

54. Moreno RH, Hogg JC, Paré PD. Mechanics of airway narrowing. Am Rev Respir Dis 1985; 133: 1171-1180.

55. Skloot G, Permutt S, Togias AG. Airway hyperresponsiveness in asthma: a problem of limited smooth muscle relaxation with inspiration. J Clin Invest 1995; 96: 23932403.

56. Shen X, Wu MF, Tepper RS, Gunst SJ. Mechanisms of the mechanical response of airway smooth muscle to length oscillation. J Appl Physiol 1997; 83: 731-738.

57. Loring SH, Drazen JM, Smith JC, Hoppin FG Jr. Vagal stimulation and aerosol histamine increase hysteresis of lung recoil. J Appl Physiol 1981; 51: 477-484.

58. Yaun H, Ingenito EP, Suki B. Dynamic properties of lung parenchyma: mechanical contributions of fiber network and interstitial cells. J Appl Physiol 1997; 83: 1420-1431.

59. Mitzner W, Blosser S, Yager D, Wagner E. Effect of bronchial smooth muscle contraction on lung compliance. $J$ Appl Physiol 1992; 72: 158-167.

60. Fredberg JJ, Jones KA, Nathan M, et al. Friction in airway smooth muscle: mechanism, latch and implications in asthma. J Appl Physiol 1996; 81: 2703-2712.

61. Gunst SJ, Meiss RA, Wu MF, Rowe M. Mechanisms for mechanical plasticity of tracheal smooth muscle. Am $J$ Physiol (Cell Physiol 37) 1995; 268: C1267-C1276.

62. Moore BJ, Verburgt LM, King CG, Paré PD. The effects of deep inspiration on methacholine dose-response curves in normal subjects. Am J Respir Crit Care Med 1997; 156: $1278-1281$.

63. Burns GP, Gibson W. Airway hyperresponsiveness in asthma: not just a problem of smooth muscle relaxation with inspiration. Am J Respir Crit Care Med 1998; 158: 203206.

64. Solway J, Fredberg JJ. Perhaps airway smooth muscle dysfunction contributes to asthmatic bronchial hyperresponsiveness after all. Am J Respir Cell Mol Biol 1997; 17: 144-146.

65. Sterk PJ, Daniel EE, Zamel N, Hargreave FE. Limited bronchoconstriction to methacholine using partial flowvolume curves in nonasthmatic subjects. Am Rev Respir Dis 1985; 132: 272-277.

66. James AD, Lougheed D, Pearce-Pinto G, Ryan G, Musk B. Maximal airway narrowing in a general population. Am Rev Respir Dis 1992; 146: 895-899.

67. Kimura $\mathrm{K}$, Inoue $\mathrm{H}$, Ichinose $\mathrm{M}$, et al. Bradykinin causes airway hyperresponsiveness and enhances maximal airway narrowing: role of microvascular leakage and airway edema. Am Rev Respir Dis 1992; 146: 1301-1305.

68. Cheung D, Van der Veen H, den Hartigh J, Dijkman JH, Sterk PJ. Effects of inhaled substance P on airway responsiveness to methacholine in asthmatic subjects in vivo. J Appl Physiol 1994; 77: 1325-1332.

69. Sont JK, Booms P, Bel EH, Vandenbroucke JP, Sterk PJ. The severity of breathlessness during challenges with inhaled methacholine and hypertonic saline in atopic asthmatic subjects. The relationship with deep-breath-induced bronchodilatation. Am J Respir Crit Care Med 1995; 152: 38-44.
70. Bel EH, Timmers MC, Dijkman JH, Stahl EG, Sterk PJ. The effect of an inhaled leukotriene antagonist, L648,051 , on early and late asthmatic reactions and subsequent increase in airway responsiveness in man. J Allergy Clin Immunol 1985; 85: 1067-1075.

71. Wagner EM. Effects of edema on small airway narrowing. J Appl Physiol 1997; 83: 784-791.

72. Malmberg P, Larsson K, Sundblad BM, Zhiping W. Importance of the time interval between FEV1 measurements in a methacholine provocation test. Eur Respir $J$ 1993; 6: 680-686.

73. Lim TK, Ang SM, Rossing TH, Ingenito EP, Ingram RH Jr. The effects of deep inhalation on maximal expiratory flow during intensive treatment of spontaneous asthmatic episodes. Am Rev Respir Dis 1989; 149: 340-343.

74. Kraft M, Djukanovic R, Wilson S, Holgate ST, Martin RJ. Alveolar tissue inflammation in asthma. Am J Respir Crit Care Med 1996; 154: 1505-1510.

75. Faul JL, Tormey VJ, Leonard C, et al. Lung immunopathology in cases of sudden asthma death. Eur Respir $J$ 1997; 10: 301-307.

76. Hamid Q, Song Y, Kotsimbos TC, et al. Inflammation on small airways in asthma. J Allergy Clin Immunol 1997; 100: 44-51.

77. Skloot G, Permutt S, Togias A. Deep inspiration affects airway caliber and airway closure in asthma. Am Rev Respir Dis 1993; 147: A257.

78. Gibbons WJ, Sharma A, Lougheed D, Macklem PT. Detection of excessive bronchoconstriction in asthma. Am J Respir Crit Care Med 1996; 153: 582-589.

79. Brusasco V, Pellegrino R, Rodarte JR. Vital capacities in acute and chronic airway obstruction: dependence on flow and volume histories. Eur Respir J 1997; 10: 1316-1320.

80. Wang JW, McFadden ER, Ingram RH Jr. Effects of increasing doses of $\beta$-agonists on airway and parenchymal hysteresis. J Appl Physiol 1990; 68: 363-368.

81. Wolkove N, Dajczman E, Colacone A, Kreisman H. The relationship between pulmonary function and dyspnea in obstructive lung disease. Chest 1989; 96: 1247-1251.

82. Bel EH, Timmers MC, Zwinderman AH, Dijkman JH, Sterk PJ. The effect of inhaled corticosteroids on the maximal degree of airway narrowing to methacholine in asthmatic subjects. Am Rev Respir Dis 1991; 143: 109-113.

83. Sont JK, Bel EH, Dijkman JH, Sterk PJ. The long-term effect of nedocromil sodium on the maximal degree of airway narrowing to methacholine in atopic asthmatic subjects. Clin Exp Allergy 1992; 22: 554-560.

84. Okazawa M, Muller N, McNamara AK, Child S, Verbrugt L, Paré PD. Human airway narrowing measured using high resolution computed tomography. Am J Respir Crit Care Med 1996; 154: 1557-1562.

85. Brown RH, Croisille P, Permutt S, Diener F, Mudge B, Togias A. Airway dilatation with lung inflation measured by HRCT. Am J Respir Crit Care Med 1997; 155: A554.

86. Mitchell HW, Sparrow MP. Video-imaging of lumen narrowing; muscle shortening and flow responsiveness in isolated bronchial segments of the pig. Eur Respir $J$ 1994; 7: 1317-1325.

87. Paré PD, Bai TR. The consequences of chronic allergic inflammation. Thorax 1995; 50: 328-332. 